http://dx.doi.org/10.5902/1984686X38355

\title{
Ensino de português a surdos em São Tomé e Príncipe: de um paradigma de exclusão até a inclusão
}

\author{
Teaching Portuguese and Deaf in São Tomé and Príncipe: from a \\ paradigm of exclusion to inclusion
}

Enseñanza de portugués a los sordos en São Tome y Principe: de um paradigma de exclusión a un paradigma de inclusíon

\author{
Sebastião Palha \\ Doutorando na Universidade Católica Portuguesa, Lisboa, Portugal. \\ sebastiao.pereirapalha@gmail.com \\ ORCID - https://orcid.org/0000-0001-8933-7758
}

\section{Ana Mineiro}

Professora doutora na Universidade Católica Portuguesa, Lisboa, Portugal.

amineiro@ics.lisboa.ucp.pt

ORCID - https://orcid.org/0000-0003-0508-7785

Recebido em 30 de maio de 2019

Aprovado em 18 de julho de 2019

Publicado em 22 de outubro de 2019

\section{RESUMO}

Em São Tomé e Príncipe e, até 2013, os surdos não iam à escola em virtude de, segundo os professores, não "aprenderem nada". Isolados, sem outros pares para comunicar, sentiam-se desprotegidos e párias numa sociedade que não os acolhia. Em 2013, em virtude das missões humanitárias de otorrinolaringologia foi detetada esta situação e proposto um projeto de inclusão educativa. A partir de um projeto de emergência linguística onde a Língua Gestual de São Tomé e Príncipe nasceu, foi criada uma turma piloto integrando os alunos do $1^{\circ}$ ciclo numa turma de surdos na escola regular. Neste processo foi elaborado um manual de português para surdos onde, partindo da Língua Gestual de São Tomé e Príncipe se iniciou um processo de implementação da literacia. Neste artigo, de metodologia descritiva, pretendemos entrelaçar os dois projetos, mostrando e discutindo as opções científicas e pedagógicas tomadas para que da exclusão se tenha conseguido a inclusão.

Palavras-chave: Literacia; Surdez; Educação inclusiva. 
http://dx.doi.org/10.5902/1984686X38355

\section{ABSTRACT}

In Sao Tome and Principe and until 2013, Deaf children did not attend to school because, according to the teachers, they did not "learn anything". Isolated, without other peers to communicate, they felt unprotected and outcast in a society that did not welcome them. In 2013, due to the humanitarian missions of otolaryngology, this situation was detected and a project for educational inclusion was proposed. From a linguistic emergency project where the Sign Language of São Tomé and Príncipe was born, a "pilot group" was created, integrating 1st enrolled Deaf students in the regular school. In this process, a Portuguese handbook for the deaf was prepared. This handbook starts from the Sign Language of São Tomé and Príncipe to the comprehension and learning a second language from a different modality. In this descriptive article, we intend to interweave the two projects, showing and discussing the scientific and pedagogical options taken so that exclusion can be achieved.

Keywords: Literacy; Deafness; Inclusive education.

\section{RESUMEN}

En Santo Tomé y Príncipe y hasta 2013, los sordos no iban a la escuela en virtud de que, según los profesores, no "aprendian nada". Aislados, sin otros pares para comunicar, se sentían desprotegidos y parias en una sociedad que no los acogía. En 2013, en virtud de las misiones humanitarias de otorrinolaringología fue detectada esta situación y propuesto un proyecto de inclusión educativa. A partir de un proyecto de emergencia lingüístic donde la Lengua Gestual de Santo Tomé y Príncipe nació, fue creada una clase piloto integrando a los alumnos del $1^{\circ}$ ciclo en una clase de sordos en la escuela regular. En este proceso se diseñó un manual de portugués para sordos, donde, empezando por el lenguaje de signos de Santo Tomé y Príncipe se inició un proceso de implantación de la alfabetización. En este artículo de metodología descriptiva pretendemos entrelazar los dos proyectos, mostrando y discutiendo las opciones científicas y pedagógicas tomadas para que de la exclusión se haya logrado la inclusión.

Palabras clave: Literacia; Sordera; Educación inclusiva.

\section{Introdução}

Segundo a World Health Organization (WHO), existem atualmente 466 milhões pessoas no mundo a viverem com perda auditiva incapacitante. Mais alarmante do que este número, é o facto de a maioria das pessoas surdas encontrarem-se em países subdesenvolvidos ou em vias de desenvolvimento. Isto significa que estes países não possuem capacidade para fornecer recursos necessários e adequados, no que diz respeito aos serviços de saúde e à educação, às pessoas com deficiência auditiva (WHO).

Por outro lado, o difícil acesso aos serviços de saúde (por exemplo, reabilitação auditiva através da colocação de próteses ou de implantes cocleares, terapia da fala, etc.) e à educação de qualidade exercerá maior impacto e posteriormente mais negativo sobre 
a pessoa surda. Este impacto acontece nos níveis funcionais - a comunicação é sempre afetada, provocando inúmeras vezes atrasos na linguagem e dificuldades na interação entre pares, sócio-emocional - a pessoa surda ao não interagir com o outro experimenta sentimentos negativos de incompreensão, frustração, revolta e raiva, levando ao isolamento social e a níveis significativamente mais baixos de auto-estima, acadêmico grandes dificuldades sentidas pelos surdos na aquisição da literacia, pela existência de barreiras na aprendizagem da leitura e escrita, e profissional - são verificadas altas taxas de desemprego devido à insuficiência de formações adaptadas à comunidade surda, contribuindo para a sua fraca autonomia.

É o caso de São Tomé e Príncipe, cujo desenvolvimento socioeconômico se revela baixo. De acordo com os dados do último Census (2012), as ilhas contavam com 187 mil habitantes dos quais 5 mil destes nasceram surdos ou adquiram surdez (MINEIRO; CARMO, 2016). É, portanto, um país onde se verifica uma alta prevalência da surdez e respostas insuficientes ou quase nulas para assistir o elevado número de casos de perda auditiva. Estes factos foram apurados no decorrer das missões de otorrinolaringologia realizadas no arquipélago, no âmbito do Saúde para Todos (Instituto Marquês Valle de Flôr - IMVF), verificando que a maioria dos casos de surdez existentes se deve a surdez neurossensorial irreversível (isto é, ao nível do ouvido interno), ao contrário do que seria expectável pelos dados da WHO que sugeria que a maioria dos casos de surdez nestes países africanos, são normalmente provocadas por quadros de infeção do ouvido médio (CAROÇA; CAMPELO; SILVA; PAÇO, 2016).

O facto de São Tomé e Príncipe ser um país extremamente dependente de ajuda externa para o desenvolvimento e demonstrar grande limitação no que concerne aos serviços e cuidados médicos, à inexistência de uma língua gestual e à falta de práticas pedagógicas especializadas para o ensino de alunos surdos, sobreveio a urgência de implementar soluções capazes de apoiar as crianças surdas visto que

as mesmas se encontravam sistematicamente rejeitadas pela escola por motivo de os seus professores não conseguirem interagir linguisticamente com as crianças e vice-versa. Estas crianças, adolescentes e jovens, quase adultos, vivem num ambiente de isolamento social, sem conviverem entre surdos. Não existia, à data do início do projeto, nenhum conhecimento entre os vários surdos, nem tampouco existe em São Tomé e Príncipe nenhuma associação de surdos (MINEIRO; CARMO, 2016, p.162). 
http://dx.doi.org/10.5902/1984686X38355

Foi assim que emergiram dois projetos importantes que procuraram, acima de tudo, alterar o paradigma de exclusão social da pessoa surda santomense através da implementação de respostas efetivas, que garantam cada vez mais a inclusão social e educativa da comunidade surda na sociedade.

\section{História e implementação de de dois projetos inclusivos: o projeto Sem Barreiras e o projeto Bámu Dá Mon}

Identificado um número acima do expectável de surdos em São Tomé e Príncipe, surgiu a necessidade de desenvolver uma solução capaz de combater a exclusão social, sentida pela comunidade surda santomense. Desta necessidade, nasceu o projeto Sem Barreiras que procurou promover a emergência da língua gestual de São Tomé e Príncipe.

O projeto Sem Barreiras, com início em 2013 e fim em 2015, teve como linha de ação principal fomentar a emergência de uma nova língua gestual em São Tomé e Príncipe. Paralelamente à primeira linha de ação, foi traçada uma segunda que consistiu na recolha do vocabulário gestual comum para posterior divulgação em contexto escolar e contexto social, isto é, junto da restante comunidade surda santomense para que esta se pudesse também apropriar desta nova língua (MINEIRO; CARMO, 2016).

Para a língua gestual de São Tomé e Príncipe emergir, foi necessário criar bases linguísticas que permitissem o seu desenvolvimento natural. Estas foram criadas através de encontros sistemáticos e diários dum grupo piloto constituído por 100 participantes, com idades compreendidas entre os 4 e 25 anos, e nenhum destes se encontrava a frequentar a escola. Os encontros aconteceram durante dois anos e foram sempre moderados por uma monitora surda que não impunha a sua própria língua, mas assegurava que fossem os próprios participantes a construir a sua própria língua, respeitando assim a sua história e cultura local (CARVALHO, 2009, 2011; MINEIRO; CARMO, 2016).

Mais tarde, já em 2014, e após análise dos gestos criados pelo grupo piloto, foi concebido o Dicionário de Língua Gestual de São Tomé e Príncipe - Dicionário Oficial da República Democrática de São Tomé e Príncipe (CARMO; OLIVEIRA; MINEIRO, 2014). Este dicionário contribuiu de forma bastante significativa para a inclusão social do grupo-alvo na sociedade civil santomense já que, de uma forma simbólica, é finalmente reconhecida à população surda santomense os seus direitos linguísticos. 
http://dx.doi.org/10.5902/1984686X38355

Ainda no ano de 2014, juntamente com o Ministério da Educação de São Tomé e Príncipe, foi desenvolvida uma resposta educativa adaptada para alunos surdos através da constituição da primeira turma (piloto) para crianças surdas. Nessa turma só com alunos surdos, as metodologias de ensino do currículo existente foram adaptadas, nomeadamente a disposição da sala de aula, os recursos visuais prevalecentes sobre a palavra escrita e a utilização em sala de aula, da nova língua gestual, modalidade totalmente adaptada à biologia destas crianças.

Nesse mesmo ano, foi constituída a Associação Santomense de Surdos com o objetivo de promover a inclusão social da pessoa surda em São Tomé e Príncipe onde, desde 2015, assegura o funcionamento do Centro de Educação para Surdos (CES) cuja atuação incide principalmente na alfabetização de jovens e adultos surdos, um grupo que é frequentemente marginalizado, uma vez que algumas das iniciativas nesta matéria se restringem a crianças em idade escolar. Este grupo é fundamental, pois grande parte da população surda não frequentou o ensino obrigatório em idade escolar, por falta de recursos no sistema de educação e ensino, na área da educação especial, e atualmente, o ensino regular já não permite 0 acolhimento destes jovens adultos.

Em 2017, no âmbito da ONGD WACT - We Are Changing Together, foi criado o projeto de cariz social Bámu Dá Mon que, em crioulo de São Tomé e Príncipe (forró), significa "vamos dar as mãos".

Em alinhamento ideológico com o projeto Sem Barreiras, o Bámu Dá Mon pretendeu contribuir para a melhoria de condições e qualidade de vida da população surda residente no arquipélago. O principal foco do Bámu Dá Mon recaiu essencialmente em potencializar o processo de ensino-aprendizagem do CES que se revelava insuficiente e desadequado.

Uma vez que o CES não se apropriava da pedagogia surda na sua essência, foi fundamental analisar a forma como era organizada a sala de aula, a metodologia adotada e ainda os materiais escolares utilizados pelo mesmo. Desta análise, concluiu-se que a sebenta criada pelo próprio centro não respeitava os parâmetros da pedagogia surda pelo que se tornou pertinente a idealização de um manual de português como língua segunda para surdos, sendo este elaborado em concordância com os princípios pedagógicos inerentes à educação de surdos. 
http://dx.doi.org/10.5902/1984686X38355

Desta forma, e com o objetivo de maximizar a intervenção do Bámu Dá Mon, foi estabelecida uma sinergia com o Instituto Marquês Valle de Flôr - IMVF, e com o apoio do UNICEF, projetou-se uma nova etapa do projeto Sem Barreiras - Bámu Dá Mon. Esta segunda etapa permitiu, em colaboração com a Universidade Católica de Lisboa, dentre diversas atividades, a elaboração e impressão do Manual de Português para Surdos, da autoria de Sebastião Palha e Ana Mineiro, e formação para docentes com impacto nacional, sobre como utilizar o manual escolar em contexto de sala de aula.

\section{Ensinar a ler e a escrever língua portuguesa a alunos surdos: opções científicas e pedagógicas}

Conhecer a língua portuguesa através da sua modalidade escrita foi uma prioridade traçada juntamente com os objetivos do Ministério da Educação e Ensino Superior em São Tomé e Príncipe. No sentido de uma maior inclusão da população surda santomense, optouse educativamente pelo português, língua oficial de São Tomé e Príncipe, assente na aprendizagem de uma segunda língua expressa através da escrita.

Tendo em conta esta linha de pensamento, tratava-se agora de saber como proceder. Foi, assim, construído um manual de ensino de português a surdos em São Tomé e Príncipe, intitulado Na escola da Rosa e do Tomé (PALHA; MINEIRO, 2019), publicado em 2019. Pedagogicamente, o manual enquadra-se na linha da mais moderna educação de surdos e ensino da língua escrita a surdos. Os surdos, ao não terem acesso à língua oral, devem assentar a sua aprendizagem na leitura e na escrita da língua portuguesa partindo de recursos e modelos visuais, tendo por base, sempre, a sua primeira língua, neste caso, a língua gestual de São Tomé e Príncipe. Tal pedagogia é absolutamente fundamental, pois se tentarmos alfabetizar um surdo da mesma forma do que um ouvinte o fracasso é certo. $O$ surdo adquirirá uma "leitura mecânica", não compreendendo o conteúdo semântico do que lê, e por conseguinte não se apropriará do verdadeiro objetivo da leitura, que não é somente conhecer as letras ou as palavras, mas o seu significado no discurso. Para isso, utilizámos recursos da pedagogia surda que se socorre de elementos visuais para atrair a atenção do aluno e cativá-lo para a aprendizagem. Um exemplo destes recursos visuais pode ser observado na figura 1. 
http://dx.doi.org/10.5902/1984686X38355

Figura 1 - Exemplo de recursos visuais

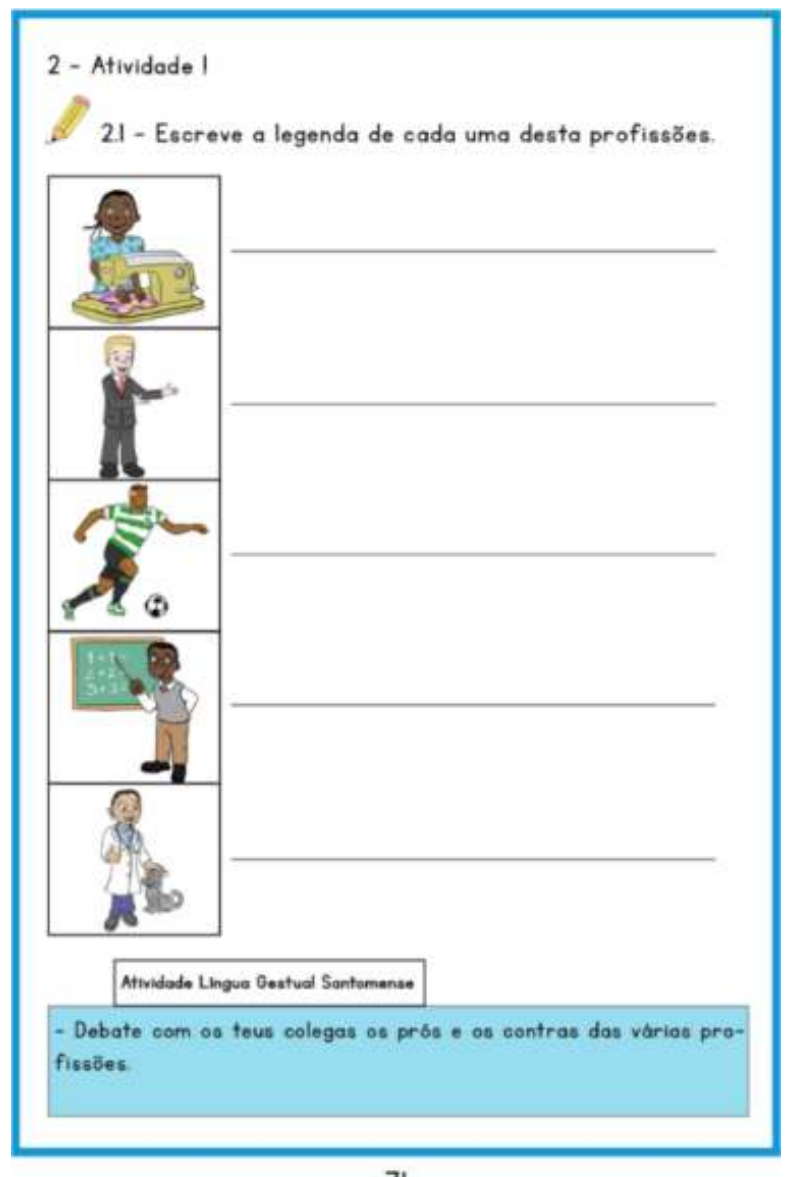

71

Fonte: Palha; Mineiro (2019).

Em Na escola da Rosa e do Tomé, houve a preocupação de trabalhar competências de leitura e de escrita do português, insistindo na compreensão dos textos que se encontram adaptados à cultura santomense e ao grau de dificuldade exigido neste nível de iniciação à leitura.

Os textos retratam temas da vida quotidiana dos surdos, a sua relação com a escola, a sua posição na família, as emoções e as suas relações com o mundo exterior. A escrita dos textos encontra-se inspirada nos textos da literatura infantil, tanto na construção de cada história como na cadência dos enunciados.

O manual é rico em ilustrações originais e todas elas foram realizadas e uniformizadas pelos dois ilustradores que se inspiraram em São Tomé e Príncipe e na sua cultura, utilizando a cor e o traço do desenho básico para a infância. Optou-se por um desenho bidimensional sem volume e centrado nas palavras e na aprendizagem sem as distrações que um desenho completo pode provocar a aprendentes surdos. 
http://dx.doi.org/10.5902/1984686X38355

O manual parte do princípio de que os surdos aprendem a leitura pelo método global, tendo em conta que a segmentação fonológica não se adequa por serem surdos. Utilizámos o método das 28 palavras que se baseia na predisposição natural da criança surda para reter o global, partindo de palavras que representam coisas concretas e despertando o interesse, levando-a à descoberta da leitura e da escrita através de histórias cativantes e uma grande diversidade de exercícios para um aprendente de língua portuguesa como língua segunda. O seguinte exercício (Figura 2) ilustra esta opção, onde através do alfabeto manual da Língua Gestual Santomense se pede aos alunos que escrevam as letras correspondentes.

Figura 2 - Exemplo de um exercício

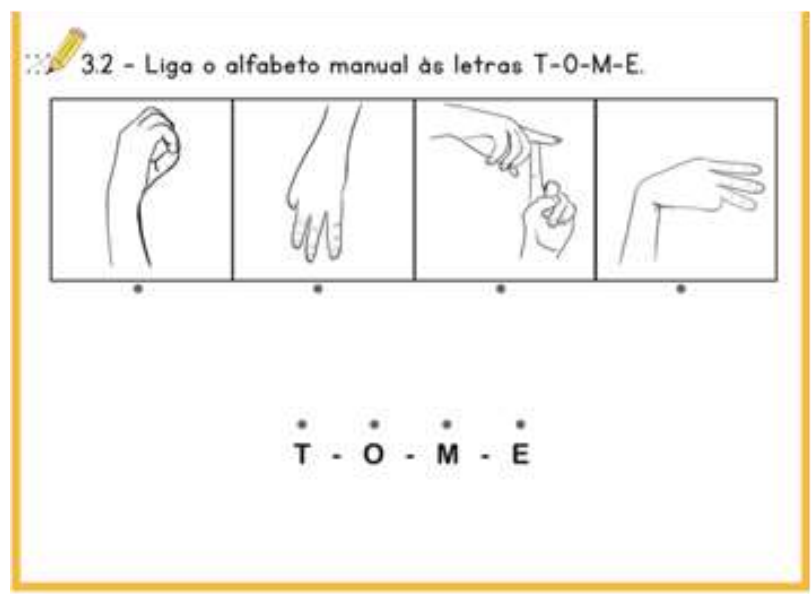

Fonte - Palha; Mineiro (2019).

Figura 3 - Enfoque do desenho sobre o texto

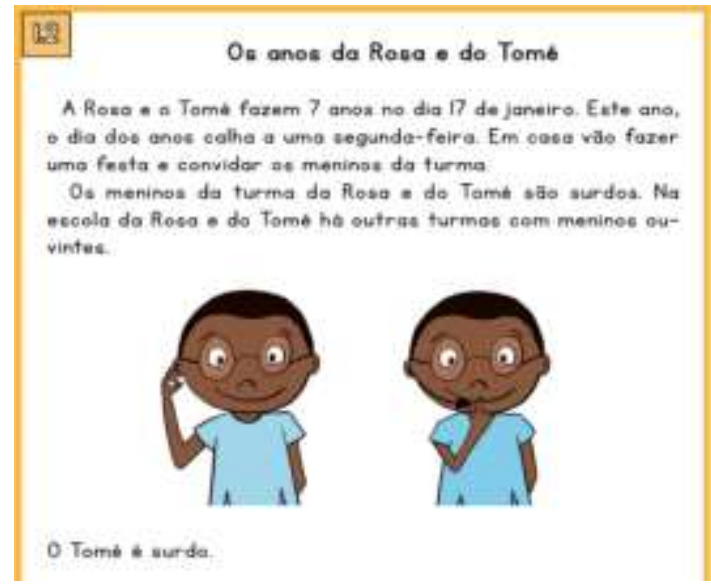

Fonte - Palha; Minerio (2019). 
O manual encontra-se dividido em três unidades: "Eu e a Escola", "Eu e a Família e a Casa" e "Eu e os Outros".

Na primeira unidade "Eu e a Escola" os objetivos da aprendizagem centram-se na criação da identidade surda, do nome gestual e do nome escrito em português assim como o auto conhecimento da idade, da data de nascimento e da nacionalidade. Como vemos no exemplo anterior (Figura 3), o desenho é maior do que a forma escrita e representa a identidade surda. Ser surdo versus ser ouvinte.

Através dos gestos da língua gestual santomense, o aluno vai aprendendo as vogais e os números, a noção de quantidade, assim como os dias da semana e a vida e rotinas da escola. No final desta primeira unidade o aluno deverá saber situar-se na escola, com os seus colegas e professores, com os outros meninos ouvintes e os que têm necessidades especiais. Saberá reconhecer as letras do alfabeto manual, escrever o seu nome gestual e o seu nome escrito em língua portuguesa, a sua idade e data de nascimento e reconhecer todas vogais e os números até 10 assim como ter noções básicas de quantidade. Também saberá identificar quais os meios de transporte para a escola e algumas localidades geográficas em São Tomé e Príncipe.

Na segunda unidade "Eu e a Família e a Casa", os objetivos são trabalhar com os alunos as cores, as emoções, a noção de família e parentesco, a casa e as suas divisões, os tempos livres e o corpo humano. Os alunos são conduzidos a interpretar e compreender os textos, assim como são levados a ordenar os elementos de frases simples e complexas adquirindo aos poucos a sintaxe da língua portuguesa. $\mathrm{O}$ aluno estará cada vez mais apto nas aprendizagens da leitura e da escrita.

$\mathrm{Na}$ terceira unidade "Eu e os Outros", reforçam-se as competências de leitura, compreensão e debate em língua gestual, originando novos gestos que são a base de aprendizagem para novas palavras. Os temas circundam as instituições públicas e a forma de comunicação dos surdos nesses locais, assim como as profissões, as viagens e a utilização do relógio. Os alunos nesta fase devem estar cada vez mais desenvolvidos com a escrita da língua portuguesa que, aos poucos, se solta da imagem e do gesto começando a estar interiorizadas as regras para ler e escrever português.

Para além de conhecer a língua portuguesa na sua modalidade escrita, era importante fomentar o bilinguismo bimodal através de uma constante interpelação da língua gestual para as tarefas de aprendizagem de leitura e de escrita do português. 
http://dx.doi.org/10.5902/1984686X38355

Foram assim concebidos exercícios ao longo do manual e ao longo das três unidades que permitem e fomentam esta bimodalidade, exercitando assim o bilinguismo que é um dos objetivos deste caminho e se insere nas opções científicas e pedagógicas que fundamentaram este manual.

No exemplo que se segue, junta-se um exemplo de um exercício (Figura 4) em que este bilinguismo bimodal é treinado, do gesto para a palavra escrita e da imagem para a palavra escrita.

Fomentar o bilinguismo assenta, também, numa opção pedagógica de desenvolver a Língua Gestual de São Tomé e Príncipe. É a partir da língua gestual que o surdo se vai situar relativamente ao mundo onde se insere, contextualizando assim as suas aprendizagens pelo que não faltou, neste manual, exercícios e atividades que tivessem em conta esta dimensão, como se pode observar na figura 5 onde apenas recorremos a animais existentes naquele país.

Figura 4 - Exercício de bilinguismo bimodal

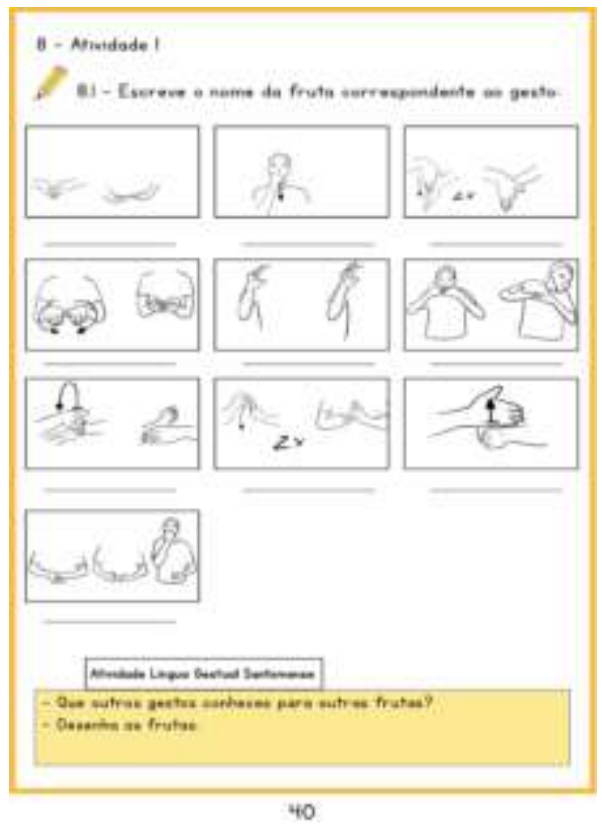

Fonte - Palha; Mineiro (2019). 
Figura 5 - Aprendizagens contextualizadas

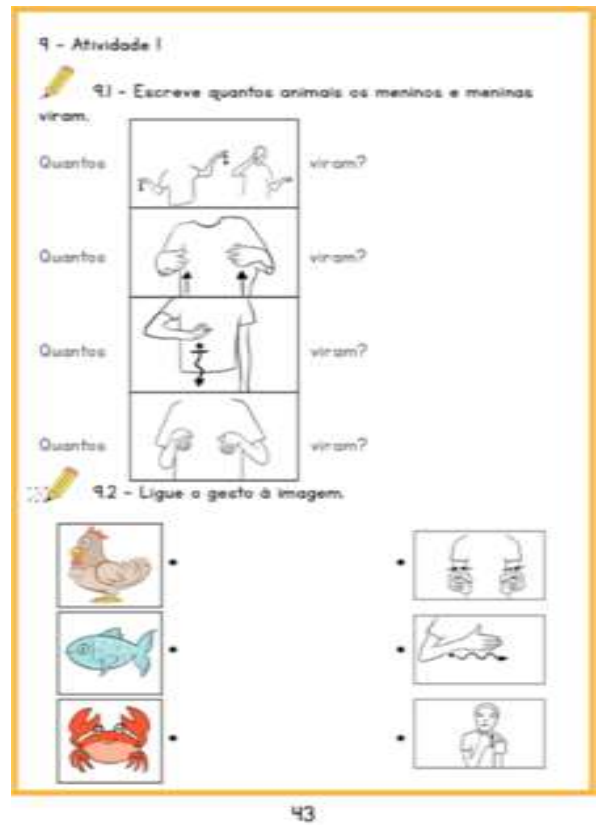

Fonte - Palha; Mineiro (2019).

Conforme se pode observar e após dos gestos se extrair as palavras correspondentes às frutas, vemos uma atividade de Língua Gestual Santomense em que se pede aos alunos que se lembrem de outros gestos para outras frutas.

A utilização deste manual desenvolveu, desde o início da sua utilização, uma grande apetência e gosto pela leitura. Todos os textos se desenvolvem à volta dos mesmos personagens que nos vão contando as suas aventuras ao longo das três unidades. A língua escrita vai ficando cada vez mais em destaque de forma gradual e relativa às aprendizagens que vão sendo feitas pelos alunos.

A complexidade e densidade textual também evolui de unidade para unidade, tal como se pode observar na figura 6 . 
Figura 6 - Evolução da complexidade e densidade textual ao longo do manual

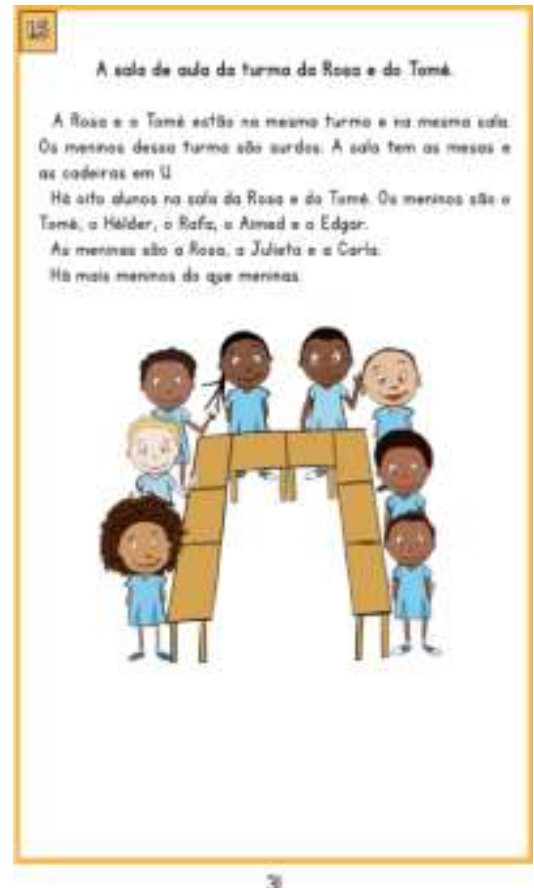

3

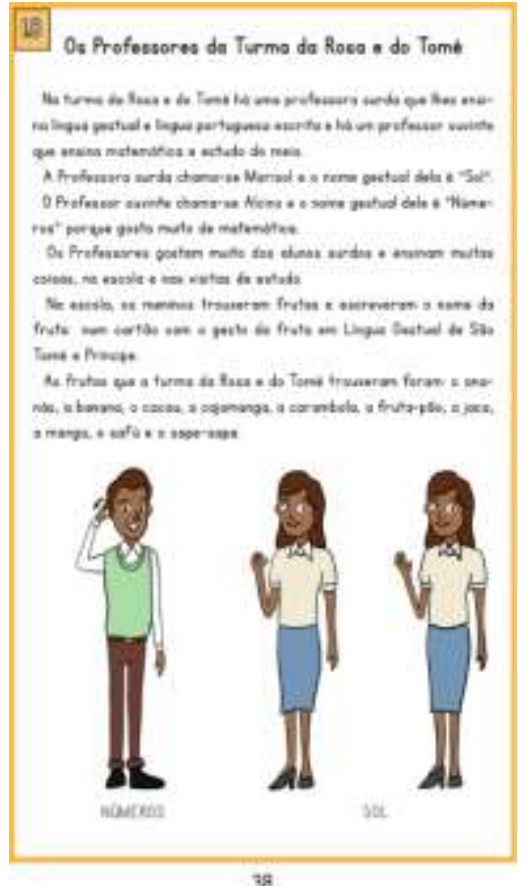

38

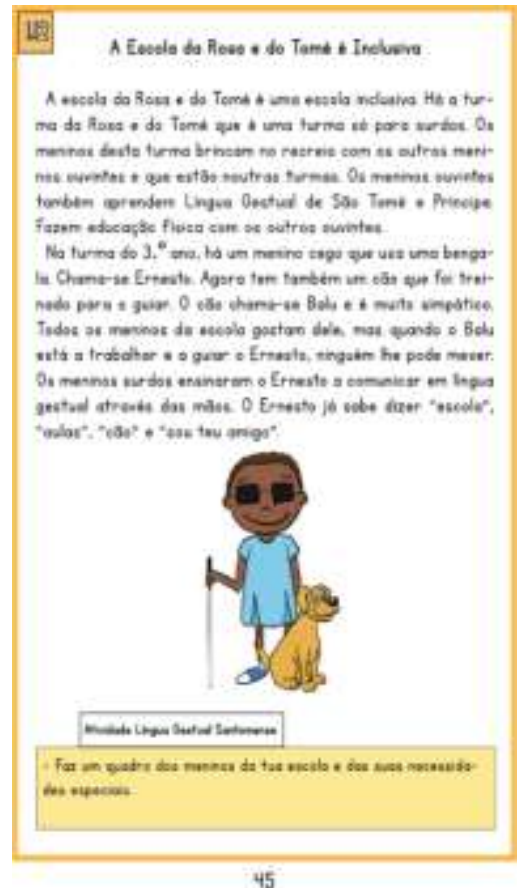

45

Fonte: Palha; Mineiro (2019).

\section{Conclusão}

Os projetos Sem Barreiras e Bamú Da Mon vieram suprir uma necessidade da sociedade santomense que se ancora no direito a uma inclusão educativa e no direito linguístico de poder comunicar numa língua de acordo com a modalidade biológica com a qual nascemos equipados.

Após a implementação destes projetos foram vistas melhorias significativas na aprendizagem das crianças surdas no meio escolar e na sociedade em geral, deixando de se sentir envergonhadas pela sua condição biológica.

Tais projetos promoveram uma chamada de atenção do governo de São Tomé e Principe que, em 2019, legislou um decreto-lei relativo à Educação Inclusiva, onde o caso dos surdos se encontra amplamente retratado.

Certo é que com bons instrumentos e com uma pedagogia adequada qualquer surdo pode aprender e sentir-se um cidadão útil, e não um peso para a sociedade. Esta foi a lição melhor aprendida de todo este processo. 


\section{Referências}

CARMO, Patrícia; OLIVEIRA, Ricardo; MINEIRO, Ana. Dicionário da Língua Gestual de São Tomé e Príncipe - Dicionário Oficial da República Democrática de São Tomé e Príncipe. Lisboa: UCEditora, 2014.

CAROÇA, Cristina; CAMPELO, Paula; SILVA, Susana Nunes; PAÇO, João. Surdez em São Tomé e Príncipe: Análise de 2 anos de missões humanitárias. Revista Portuguesa de Otorrinolaringologia e Cirugia Cérvico-Facial, Lisboa, n. 1, Vol. 54, p. 5 -11, mar. 2016.

CARVALHO, Paulo. História de Educação de Surdos, I. Lisboa: UCEditora, 2009.

CARVALHO, Paulo. História de Educação de Surdos, II. Lisboa: UCEditora, 2011.

INSTITUTO NACIONAL DE ESTATÍSTICA SÃO TOMÉ E PRÍNCIPE. IV recenseamento geral da população e da habitação 2012 (iv rgph 2012) - resultados nacionais. São Tomé, São Tomé e Príncipe; INESTP: 2013.

MINEIRO, Ana; CARMO, Patrícia. Língua Gestual de São Tomé e Príncipe: retrato dos primeiros gestos. Revista de Estudos Linguísticos da Universidade do Porto, Porto, vol. 11, p. 161-182, 2016.

PALHA, Sebastião; MINEIRO, Ana. Na Escola da Rosa e do Tomé - Manual de Português para Surdos. Lisboa: UCEditora e Instituto Marquês Valle de Flôr, 2019.

WORLD HEALTH ORGANIZATION. In: https://www.who.int/deafness/en/. Acesso em: 29 mai. 2019.

\section{Correspondência}

Sebastião Palha - Instituto de Ciências da Saúde, Universidade Católica Portuguesa (UCP), Palma de Cima, 1649-023, Lisboa, Portugal.

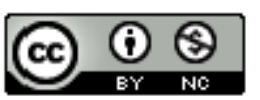

This work is licensed under a Creative Commons Attribution-NonCommercial 4.0 International (CC BY-NC 4.0) 